\title{
NEWS
}

\section{Climate-control plans scrutinized}

The Royal Society reviews options for fighting global warming with geoengineering.

As atmospheric levels of carbon dioxide soar and political efforts to control emissions stagnate, one scientific academy says that it is time to consider radical intervention.

On 1 September, the Royal Society, Britain's premier scientific organization, released its first analysis of a host of controversial methods for intentionally altering Earth's climate. Such approaches, known broadly as geoengineering, could slow or halt climate change by either restricting the amount of sunlight heating Earth's surface or reducing levels of carbon dioxide in the atmosphere.

But they could also have disastrous side effects, such as stifling

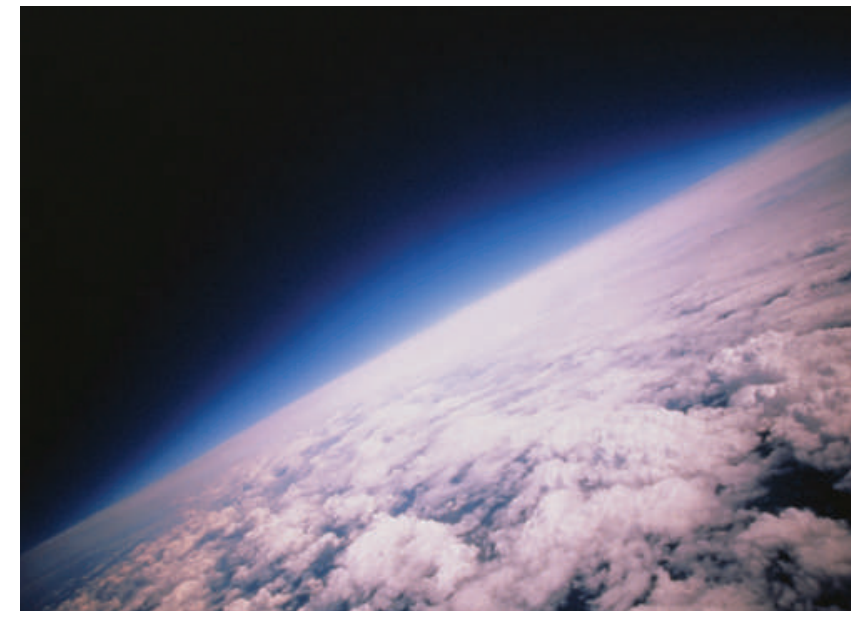

Geoengineering ideas include using sea salt to brighten clouds. the Asian monsoons or altering the oceans' oxygenation or $\mathrm{pH}$. For these reasons, the society is calling for international regimes to review even preliminary research projects. Further work, it says, must also go into developing rules for how and when geoengineering might be used.

Because the science and policy surrounding geoengineering is so complex, any potential scheme would take decades to put into practice, says John Shepherd, an Earth scientist at the University of Southampton, UK, who chaired the report. "These things may help us get out of a fix later in the century," he says. "But we have to do research now."

Geoengineering proposals have been around for decades, but most have been dismissed out of hand because they often seem outlandish, costly or downright dangerous. Some researchers see the Royal Society report as the first real indication that geoengineering is being taken seriously. "This is actually quite a big deal," says David Keith, an environmental engineer at the University of Calgary in Alberta, Canada, and one of a dozen authors on the study. The report is "the first major national academy report solely devoted to this topic", he says.

Shepherd stresses that the Royal Society wasn't trying to pick winners and losers among possible geoengineering approaches, but the group did weigh in with which concepts they consider the most promising for future study (see 'Thinking big'). Some popular ideas received low marks. The idea that painting roofs white could cool urban areas - proposed among others in a 27 August geoengineering report by the UK Institution of Mechanical

Engineers - would produce a near-negligible change in Earth's overall temperature, the Royal Society argued. Also low on the list was using iron to increase carbon-absorbing algal blooms in the ocean. Such algal outbreaks would absorb relatively little carbon, the new study warns, and would consume vast amounts of oxygen, potentially leading to oceanic 'dead zones'.

Other ideas were viewed more favourably. Artificial weathering, the acceleration of geological carbon-absorbing processes, was among the most promising ways to capture carbon, according to the panel. Filling agricultural land with carbonate and silicate compounds

\section{Thinking big}

Five ideas for engineering the planet.

Stratospheric aerosols Spraying the atmosphere with sulphates is risky, but could cool the planet quickly.

Air capture Man-made scrubbers to remove carbon dioxide directly from the air could work, but are likely to be expensive.

Cloud brightening Spraying sea salt into the sky to brighten clouds would only cool the region below.

Enhanced weathering using silicates or carbonates to absorb $\mathrm{CO}_{2}$ could work, but more study is needed.

Space reflectors to cool Earth would cost trillions of dollars. The panel recommends keeping space-based research desk-based for now. could turn fields into carbon sponges, absorbing massive amounts of carbon dioxide. And seeding the stratosphere with sulphate aerosols - a process that would increase the atmosphere's reflectivity - could mimic the immediate cooling effects of major volcanic eruptions. The sulphate strategy has the advantage of being a quick way to cool the planet, Shepherd says. But to keep it cool, "you have to keep it going for many decades or possibly centuries", he says. "There is no silver bullet."

\section{Dangerous distraction}

Most of the top-ranked strategies do have potentially catastrophic side effects. Some models suggest that putting sulphates into the stratosphere could degrade the ozone layer or alter the monsoons - affecting the livelihoods of billions of people. Using silicate or carbonate compounds, meanwhile, could alter the $\mathrm{pH}$ of soil or marine ecosystems, depending on how researchers dispose of the material. For these reasons, experiments must undergo stringent ethical review and public discussion, says Michael Oppenheimer, a geoscience and policy researcher at Princeton University in New Jersey who reviewed the study. "Scientists should not take a step in the direction of field experiments until these issues are resolved," he warns.

Panel members acknowledge that the biggest risk from geoengineering may be that it distracts from the main accepted way of stopping climate change: reducing the amount of greenhouse gases being spewed into the atmosphere. "Geoengineering is already being seen as an easy way out," warns Doug Parr, chief scientist of environmental campaigners Greenpeace UK. Shepherd agrees that geoengineering is no substitute for curbing fossil-fuel use and developing alternative energy sources. "In [the panel's] view, the primary focus has to remain on conventional emissions," he says.

For now, Shepherd thinks that a modest annual expenditure of around $£ 10$ million (US\$16 million) should be enough to determine which schemes hold the most promise. "In five to ten years' time," Shepherd predicts, "we'll have an idea whether it's worth spending serious research money on this."

Geoff Brumfiel 